Article

\title{
Evaluating the Drought Endurance of Landscaping Ground Cover Plants in a Roof Top Model
}

\author{
Nath Pichakum ${ }^{1}$ and Aussanee Pichakum ${ }^{2, *(D)}$ \\ 1 Department of Horticulture, Faculty of Agriculture, Kasetsart University, Chatuchak, \\ Bangkok 10900, Thailand; nath.p@ku.th \\ 2 Department of Plant Science, Faculty of Science, Mahidol University, Rajthevi, Bangkok 10400, Thailand \\ * Correspondence: aussanee.pic@mahidol.ac.th
}

Citation: Pichakum, N.; Pichakum, A. Evaluating the Drought Endurance of Landscaping Ground Cover Plants in a Roof Top Model. Horticulturae 2021, 7, 31. https://doi.org/10.3390/ horticulturae7020031

Academic Editor: Genhua Niu

Received: 27 November 2020

Accepted: 29 January 2021

Published: 13 February 2021

Publisher's Note: MDPI stays neutral with regard to jurisdictional claims in published maps and institutional affiliations.

Copyright: (c) 2021 by the authors. Licensee MDPI, Basel, Switzerland. This article is an open access article distributed under the terms and conditions of the Creative Commons Attribution (CC BY) license (https:/ / creativecommons.org/licenses/by/ $4.0 /)$.
Abstract: Vegetative ground covers are commonly used in urban, tropical roadside gardens. Such landscaping ground covers usually encounter extreme water-deficits and high temperatures from vehicles and urban infrastructures. However, information about the plant species that are appropriate for low maintenance gardens is not available, especially in tropical areas. This study aimed to investigate potential indicators for evaluating plant tolerance to water-deficit situations. A nonirrigated rooftop model was used to test 25 commercial ground cover species in a greenhouse at Mahidol University, Nakhon Pathom Province, Thailand. Each of these 25 species was potted and subjected to one of two conditions: with or without irrigation for 7 days. Physiological responses relevant to plant endurance during water-deficits were monitored, including changes in leaf relative water content (RWC), percent stomatal opening, leaf surface temperature, leaf total chlorophyll content, leaf greenness, maximum quantum yield, and light quantum yield. Moreover, an additional indicator of landscape utility was evaluated, where each species was judged by trained panelists for their esthetic appeal. Diverse responses were observed based on the type of physiological parameter measured, plant species, and duration of drought conditions. Water withdrawal for three days was deemed an appropriate time to determine plant tolerance to water-deficit conditions, as signs of stress were clearly observed in three parameters, i.e., changes in leaf RWC, percent stomatal opening, and esthetic score. Lastly, cluster analysis revealed that seven plant species were appropriate for tropical, urban ground covers, as they had high endurance under water-deficit conditions, namely, Allium schoenoprasum, Liriope muscari, Aloe sp., Sedum x rubrotinctum, Alternanthera ficoidea, Pilea libanensis and Plectranthus scutellarioides.

Keywords: photosynthesis; stress response; drought tolerance; low maintenance gardens

\section{Introduction}

The mean maximum urban heat island intensity in three major cities in Thailand had positive thermal contrasts, indicating that the air temperatures at the urban sites were higher than at rural sites [1]. The present expansion of city area is intensifying the urban heat island phenomenon, and the high ambient temperatures radiating from concrete infrastructure and buildings are problematic to the living standards of city residents. Moreover, current climate change and uncontrolled pollution are exacerbating the problem. Thus, recovering green space is becoming increasingly critical for maintaining environmental quality.

Establishing vegetation on rooftops can provide numerous ecological and economic benefits [2]. Rapid urban population growth and development is largely associated with mass transportation. Roads and highways occupy a great deal of land, alter the surrounding landscape immensely, diminish natural systems, and disrupt life cycles sharply. Roadside vegetation is one of the most important elements of scenic beauty along highways [3]. Regular maintenance of roadside plants by watering, applying fertilizers and pesticides, 
weeding, trimming, pruning, and planting is often minimal in Thai cities because operational costs in city zones are around 3.5 times higher than in rural areas. This problem can be partly addressed by taking advantage of highly tolerant plants that are more suitable for sites with limited maintenance. Ground cover plants are low-growing and spread easily and are suitable for places such as dry slopes, parking strips, traffic islands and curbsides. A variety of ornamental features adds visual interest to landscapes and provides a variety of textures and colors, and it also helps to reduce soil erosion and provide transitions between landscape space [4].

Environments that experience high solar radiation and gardens receiving low maintenance are examples of unfavorable conditions that result in plant stress. Generally, plants have various adaptations to improve endurance, such as fibrous roots, thick leaves, or small leaf size. A wide range of different environmental conditions like drought, heat, and flooding is known to interrupt plant growth and development, and all plant species must maintain homeostasis, which can lead them to switch on adaptive mechanisms under survival mode. For example, drought-exposed plants lose high amounts of water, resulting in an imbalance between leaf transpiration and root absorption. Pansy (Viola $\times$ wittrockiana) exposed to drought stress express various responses at the physiological and biochemical levels, such as decreased relative water content (RWC), which is an important indicator reflecting the water balance between supply and loss in plants, total chlorophyll, and antioxidants [5]. Plants can respond to water stress through dramatically complex mechanisms, from genetic molecular expression to biochemical metabolism through physiological processes of individual plants and to ecosystem-level processes. Examples include drought escape by completing a life cycle before severe water deficiency occurs, drought avoidance by enhancing water uptake ability, drought tolerance mainly through osmotic adjustment ability and maintaining tissue turgidity, drought resistance through altering metabolic pathways to increase survival under severe stress, drought abandonment by discarding a part of the individual plant, and the evolution of drought-tolerant biochemical-physiological traits in drought-prone plants [6].

Plants have evolved a number of adaptive mechanisms that allow their photochemical and biochemical systems to cope with negative changes in the environment, like waterdeficiencies, and this acquisition includes both phenotypic and genotypic changes. Several approaches have been made to identify the plant traits that are most sensitive to drought [7]. For example, total osmotic adjustment increased with increasing drought stress severity in olive (Olea europaea L.) trees. Osmotic adjustment is what allows leaves to regulate leaf water potentials. Moreover, stomatal conductance and the net photosynthetic rate declined with increasing drought stress. This study concluded that osmotic adjustment in olive trees was associated with osmotic regulation of drought tolerance, providing an important mechanism for avoiding water loss. The study conclusively demonstrated that plants under high drought stress showed greater total osmotic adjustments [8], which indicates that total osmotic adjustment may be a useful trait for identifying tolerant plants.

The selection for tolerance is useful for improving genetic properties in important horticultural crops worldwide. The validity and effectiveness of criteria for classifying tolerance is especially important given the wide range of determinant, endogenous mechanisms found among plants. In the selection of salt-tolerant tomato (Lycopersicon esculentum L.) plants, $\mathrm{K}+/ \mathrm{Na}+$ ratio and sucrose (which indicated the importance of lipid peroxidation) were specific nutritional and biochemical indicators of salt stress [9]. According to cluster analysis with multiple agronomic parameters at all growth stages of 13 wheat (Triticum estivum L.) genotypes exposed to 4 salinity levels, 3 genotypes were reported as the most tolerant to salinity [10].

Regardless of the desired esthetic effect, annual climate and microclimate have a major impact on plant selection. In particular, high and low temperatures, irradiation, wind, and the amount and distribution of precipitation will determine which species can survive in a specific area [11]. Generally, maintaining cultivated plants in tropical landscapes requires an enormous amount of irrigated water, which can be very costly. Current climate change 
also has aggravated the problems of managing landscape plants, especially underwaterlimited conditions, so the use of drought-tolerant species will assist landscape designers in creating low-maintenance, sustainable gardens that require minimal watering. However, there are few reports on drought-tolerant ground cover plants in tropical areas. Evaluation of drought endurance requires reliable and accurate indicators or parameters, as well as standardized methodology. This study aimed to investigate the physiological traits and endurance of different ground cover species under water-deficit conditions, providing a potential method to evaluate such plant species. Moreover, the plant species with the highest endurance for limited-irrigation conditions are reported.

\section{Materials and Methods}

\subsection{Plant Materials}

A total of 25 commercial plant species suitable for ground cover (e.g., low-growing) were purchased from a local distributor, namely, DOC Nursery, Bangkok, Thailand [12]. The tolerance properties of some of the species had previously been reported (Table 1). For each plant species, healthy mature plants (obtained from cuttings of the original, purchased plant) were grown in $10 \times 10 \mathrm{~cm}$ plastic pots filled with a commercial mixed media that consisted of very fine composted soil, rice husk, rice husk ash, and chopped coconut husk. The basic properties of the planting media were analyzed and found to have $49 \%$ moisture content as measured by volumetric method, $0.323 \mathrm{~g} \mathrm{~cm}^{-3}$ density, $149 \mathrm{~m} \mathrm{day}^{-1}$ hydraulic conductivity, pH 6.7, $0.133 \mathrm{dS} \mathrm{m}^{-1} \mathrm{EC}, 29.3 \mathrm{cmol} \mathrm{kg}^{-1} \mathrm{CEC}$, and $19.1 \%$ organic matter. A slow-release fertilizer (4 g 14-13-13 NPK) was added to each pot after transplanting.

\subsection{Environmental Conditions}

The plants were acclimatized for 7 days in a greenhouse with automated sprinkler irrigation at Mahidol University, Nakhon Pathom Province, Thailand $\left(13^{\circ} 47^{\prime} 36.26^{\prime \prime} \mathrm{N}\right.$, $100^{\circ} 19^{\prime} 21.05^{\prime \prime} \mathrm{E}$ ). The experiment was conducted during June-October 2018, and the exposed nature of the greenhouse (with mesh siding and a plastic roof) allowed study plants to be exposed to Thailand's tropical hot climate. Average light intensity in the greenhouse was $766 \mu \mathrm{mol} \mathrm{m}^{-2} \mathrm{~s}^{-1}$, and the average minimum and maximum air temperatures were $25^{\circ} \mathrm{C}$ and $49^{\circ} \mathrm{C}$, respectively; data were obtained with a HOBO data logger (Pendant ${ }^{\circledR}$, Temperature/Light $64 \mathrm{~K}$, Bourne, Massachusetts, USA) placed at the same level as the study plants. An overhead sprinkler system distributed water evenly over the experimental area. Daily watering (approximately $200 \mathrm{~mL} \mathrm{pot}^{-1}$ ) occurred at $7 \mathrm{am} 12 \mathrm{pm}$, and $5 \mathrm{pm}$. Irrigation was performed daily every 10 am at the level of container capacity (field capacity), as measured by a 3-in-1 digital $\mathrm{pH} /$ moisture/sunlight plant Soil Mate meter (ETP306, Japan) at a $6 \mathrm{~cm}$ depth.

On the first day of the experiment, 20 uniform plants of each species were divided into 2 groups. Plants in the first group were moved under a transparent plastic shelter in order to prevent them from being irrigated by the overhead sprinkler, forming the water-deficient treatment or non-irrigated rooftop model [33]. Plants in the other group remained exposed to daily watering from the overhead sprinkler, forming the control or well-watered treatment. Temperatures under the plastic shelter were slightly higher (average minimum and maximum air temperatures of $25^{\circ} \mathrm{C}$ and $51^{\circ} \mathrm{C}$, respectively) than the air around the control plants (average minimum and maximum air temperatures of $25^{\circ} \mathrm{C}$ and $49{ }^{\circ} \mathrm{C}$, respectively). Of the 10 plots per treatment per species, 5 pots were reserved for nondestructive measurements and the other 5 for destructive sampling. Plant responses and soil moisture percentage were evaluated between 9 and 11 am at 5 times; 0 (starting day), $1,3,5$, and 7 days after the start of the experiment. 
Table 1. List of the 25 studied plant species with recent information on tolerance abilities.

\begin{tabular}{|c|c|c|}
\hline No & Scientific Name & Landscaping Features/Reference \\
\hline 1 & $\begin{array}{c}\text { Hemigraphis alternata (Burm.f.) T. Anderson (Syn.) } \\
\text { (Strobilanthes alternata (Burm.f.) Moylan ex J.R.I. Wood) }\end{array}$ & Low maintenance [13] \\
\hline 2 & Alternanthera bettzickiana (Regel) G. Nicholson & - \\
\hline 3 & Alternanthera ficoidea (L.) P. Beauv. & Low maintenance [14] \\
\hline 4 & Allium schoenoprasum L. & Low maintenance [15] \\
\hline 5 & Zephyranthes candida (Lindl.) Herb. & Medium maintenance [16] \\
\hline 6 & Trachelospermum jasminoides (Lindl.) Lem. & $\begin{array}{l}\text { Medium maintenance and heavy shade } \\
\text { tolerance [17] }\end{array}$ \\
\hline 7 & Liriope muscari (Decne.) LH. Bailey & Drought and air pollution tolerance [18] \\
\hline 8 & Aloe sp. & Low maintenance and drought tolerance [19] \\
\hline 9 & Dianella caerulea Sims & Low maintenance and drought tolerance [20] \\
\hline 10 & Achillea millefolium L. & Heat and drought tolerance [21] \\
\hline 11 & Coreopsis rosea Nutt. & Drought tolerance [22] \\
\hline 12 & Leucanthemum vulgare (Vaill.) Lam. & Drought tolerance [23] \\
\hline 13 & Cyanotis obtusa (Trimen) Trimen (Syn.) & Drought tolerance [24] \\
\hline 14 & Convolvulus sabatius Viv. & Drought tolerance [25] \\
\hline 15 & Sedum $x$ rubrotinctum R.T. Clausen & Drought tolerance [26] \\
\hline 16 & Fimbristylis ovata (Burm.f.) J.Kern & - \\
\hline 17 & Rhynchospora nervosa (Vahl) Boeckeler & - \\
\hline 18 & Eleocharis sp. & Low maintenance [27] \\
\hline 19 & Acalypha wilkesiana Müll.Arg. & Low maintenance [28] \\
\hline 20 & Plectranthus scutellarioides (L.) R.Br. & Low maintenance [29] \\
\hline 21 & Heterocentron elegans Kuntze & Partial drought tolerance [30] \\
\hline 22 & Phyllanthus myrtifolius (Wight) Müll.Arg. & - \\
\hline 23 & $\begin{array}{c}\text { Pennisetum setaceum (Forssk.) Chiov. (Syn.)(Cenchrus } \\
\text { setaceus (Forssk.) Morrone.) }\end{array}$ & $\begin{array}{l}\text { Low maintenance and air pollution tolerance } \\
\qquad[31]\end{array}$ \\
\hline 24 & Pilea libanensis Urb. & - \\
\hline 25 & Lantana camara $\mathrm{L}$. & Low maintenance and drought tolerance [32] \\
\hline
\end{tabular}

\subsection{Plant Longevity}

The utility of landscape plants includes both longevity and esthetic appeal. Top-view photos were taken of each study plant at a distance of $30 \mathrm{~cm}$ from the plant, and then, for each plant species, 10 photographs from each of the 5 time intervals were arranged on the same frame to compare the physical state of plants from each treatment. Fifty young landscape designers, ages 18-20 years old, assessed esthetic appeal by scoring each photograph: 3 = good (healthy plant exhibiting a vigor comparable to the starting day), 2 = intermediate (plant showing visible brown areas, with $<20 \%$ of total leaf area appearing unhealthy), $1=$ poor (stressed plant with $>20 \%$ of total leaf area appearing unhealthy, brown, or wilted). An average score of 2.00-3.00 meant the plant species was likely suitable for landscape use, while those with scores $<2.00$ were deemed unlikely to be appropriate for landscape use. The scores for each plant species were calculated relative to the initial score value of plants on day 0 . 


\subsection{Physiological Responses}

Physiological traits related to stress exposure that were measured included relative water content (RWC) of leaves, percent stomatal opening, and leaf temperature. RWC was evaluated following Turner [34] from mature leaves that were randomly collected from near the shoot apex. Three leaves per plant were measured. Values were standardized by using the RWC of each leaf relative to the RWC on day 0 in order to calculate an index of RWC.

Percent stomatal opening was quantified from mature leaves that were selected as described above with RWC. The lower side of the leaf blade was coated with nail polish, and the dried polish was lifted with clear adhesive tape. Stomata were observed under a light microscope (Olympus BX53, Tokyo, Japan) by taking photographs, and stomata length were measured using ImageJ [35]. The change in the percentage of stomata open was standardized relative to the percentage of stomata open on day 0 .

The temperature of the leaf surface was measured using a FLIR ONE thermal imaging camera (FLIR systems Gen2, Wilsonville, Oregon, USA) connected to a cell phone equipped with the FLIR ONE application. Top-view photos were taken at a distance of $30 \mathrm{~cm}$ from each study plant, and the average temperature was then obtained from the FLIR Report Studio program.

\subsection{Plant Health}

Plant response to stress was monitored via maximum quantum yield ( $\mathrm{Fv} / \mathrm{Fm})$ and photosynthetic potential, which shows the maximum dark-adapted photochemical efficiency of photosystem II (PSII), using the Hansatech fluorescence monitoring system (FMS2, Norfolk, UK). The examined leaves were chosen using the same methods as employed when selecting leaves for the RWC and stomata components described above. The changes in $\mathrm{Fv} / \mathrm{Fm}$ and PSII were calculated as percentages relative to the initial values on day 0 .

\subsection{Color Appearance}

The external appearance of leaf color is another component reflecting the utility of landscape plants. Leaf color is associated with various pigment compounds such as chlorophyll, carotenoids, and anthocyanins, and recently many reports have quantified the amount of each pigment by color meter measurement. Total chlorophyll content in mature leaves was determined as described by Sumanta et al. [36], with leaf selection using the same sampling method as described above for RWC. In short, a small piece of leaf flesh was weighed and extracted with $1 \mathrm{~mL}$ dimethyl sulfoxide before being incubated in the dark for 3 days or until the leaf sample turned fully transparent. The supernatant was then measured by spectrophotometer (Hitachi double beam spectrophotometer model U2900, Tokyo, Japan) at 665 and $649 \mathrm{~nm}$. Total chlorophyll content was calculated as the sum of chlorophyll $\mathrm{a}$ and $\mathrm{b}$ expressed in terms of $\mathrm{mg} \mathrm{g}^{-1}$ dry weight. Leaf greenness was also estimated using a Konica Minolta chlorophyll meter SPAD-502 Plus (Konica, Osaka, Japan) expressed as SPAD units on randomly sampled leaves as previously described for RWC. Both total chlorophyll content and leaf greenness degree were calculated as percentages relative to the values obtained on day 0 .

\subsection{Data Analysis}

Statistical analyses were performed using SPSS IBM version 22. Daily values of each parameter were calculated as a relative value to the control $(100 \%)$ at starting day (day 0$)$ of corresponding plant species. A Student's t-test was used to statistically separate the drought from the well-irrigated plant of each species. Mean values and standard errors are shown. All response parameters of each treatment were further analyzed using the hierarchical cluster analysis in SPSS. 


\section{Results}

\subsection{Plant Response to Water Deficits}

The water-deficit tolerance of the 25 groundcover landscape plant species studied varied. Plant species with an esthetic score of $>2.00$ and whose esthetic scores were not significantly different between experimental (i.e., drought) and control (i.e., with irrigation) conditions were considered to have acceptable tolerance as a landscaping plant, and all study plants could be classified into one of three groups based on their significant survival period. First, eight plant species, i.e., A. schoenoprasum, L. muscari, C. obtusa, Aloe sp., S. $x$ rubrotinctum, P. libanensis, P. scutellarioides and Alt. Ficoidea showed high tolerance to drought for five days. Among this group, A. schoenoprasum, L. muscari, C. obtusa, Aloe sp., and $S . x$ rubrotinctum showed the highest endurance to limited water, with esthetic scores of $2.12,2.48,2.56,2.90$ and 2.94, respectively, on day 7 (Table A1). The second group tolerated drought for three days and were considered to have intermediate tolerance, including Eleocharis sp., F. ovata, Z. candida, P. setaceum, P. myrtifolius, and Alt. bettzickiana. Lastly, the remaining 11 plant species were only able to survive a short time (1-2 days) after water withdrawal, indicating they are very sensitive to drought, including L. vulgare, R. nervosa, A. wilkesiana, T. jasminoides, C. rosea, A. millefolium, D. caerulea, C. sabatius, $H$. alternate, $H$. elegans and L. camara. In particular, two plant species, H. elegans and L. camara wilted rapidly after no longer being irrigated, with low moisture levels in the growing media $(10 \%$ on day 3$)$.

The average soil moisture percentage on day 3 was $59-78 \%, 49 \%$, and $10-20 \%$ in the high, intermediate and sensitive groups, respectively, reflecting their different endurance capabilities under drought stress. In this non-irrigated rooftop model, eight of the studied plant species could tolerate water withdrawal for at least five days, while the other species were able to withstand drought for shorter periods. Thus, exposing plants to water-deficit conditions for three days appeared to be a suitable time length for determining endurance ability to water-deficits under a non-irrigated rooftop model. Figure 1 illustrates the relative index score representing esthetic appearance between plants that did and did not receive irrigation for each plant species on day three of the experiment. The tolerant group with high scores (such as L. muscari, S. x rubrotinctum, Alt. ficoidea, and Aloe sp.) did not show significant differences between the two treatments on day 3 , and had values that were similar to the initial values on day 0 (i.e., relative index scores near 100). In contrast, plant species in the sensitive group (such as L. camara, C. sabatius, and H. elegans) had low relative index scores $(<40)$.

The physiological responses that were related to the homeostasis of plant water retention were leaf relative water content (RWC) index, percent stomatal opening and leaf surface temperature. Figure 2A shows leaf RWC on day three; the irrigated plants of each species performed well in terms of growth and development, as indicated by high RWC index values that were nearly the same as the initial values. Alt. bettzickiana and Aloe sp. had high scores on day three, and the two treatments were not significantly different, while $R$. nervosa and $C$. sabatius belonged to the sensitive group, which had low leaf RWC. Interestingly, percent stomatal opening could be clearly separated into two groups (Figure 2B). First, 12 plant species (P. myrtifolius, P. libanensis, Z. candida, P. setaceum, Alt. ficoidea, C. rosea, Alt. bettzickiana, Aloe sp., S. x rubrotinctum, F. ovata, A. wilkesiana and A. schoenoprasum) had high stomatal opening above $94 \%$ underwater-deficient conditions, similar to the control group. For the remaining plant species, a significant difference between plants with and without irrigation gradually diverged from $11.7-89.8 \%$ stomatal opening in C. sabatius, L. camara, T. jasminoides, H. alternate, L. vulgare, R. nervosa, D. caerulea, C. obtuse, A. millefolium, H. elegans, P. scutellarioides, Eleocharis sp. and L. muscari. Finally, leaf surface temperature varied within plant species. Most water-limited plants had a higher leaf temperature on day three than on day zero (Figure 2C), especially L. vulgare, $L$. camara, C. rosea and D. caerulea, which were classified in the sensitive group, with relative leaf temperature $13-17 \%$ higher in the water-limited group compared to the control group. 


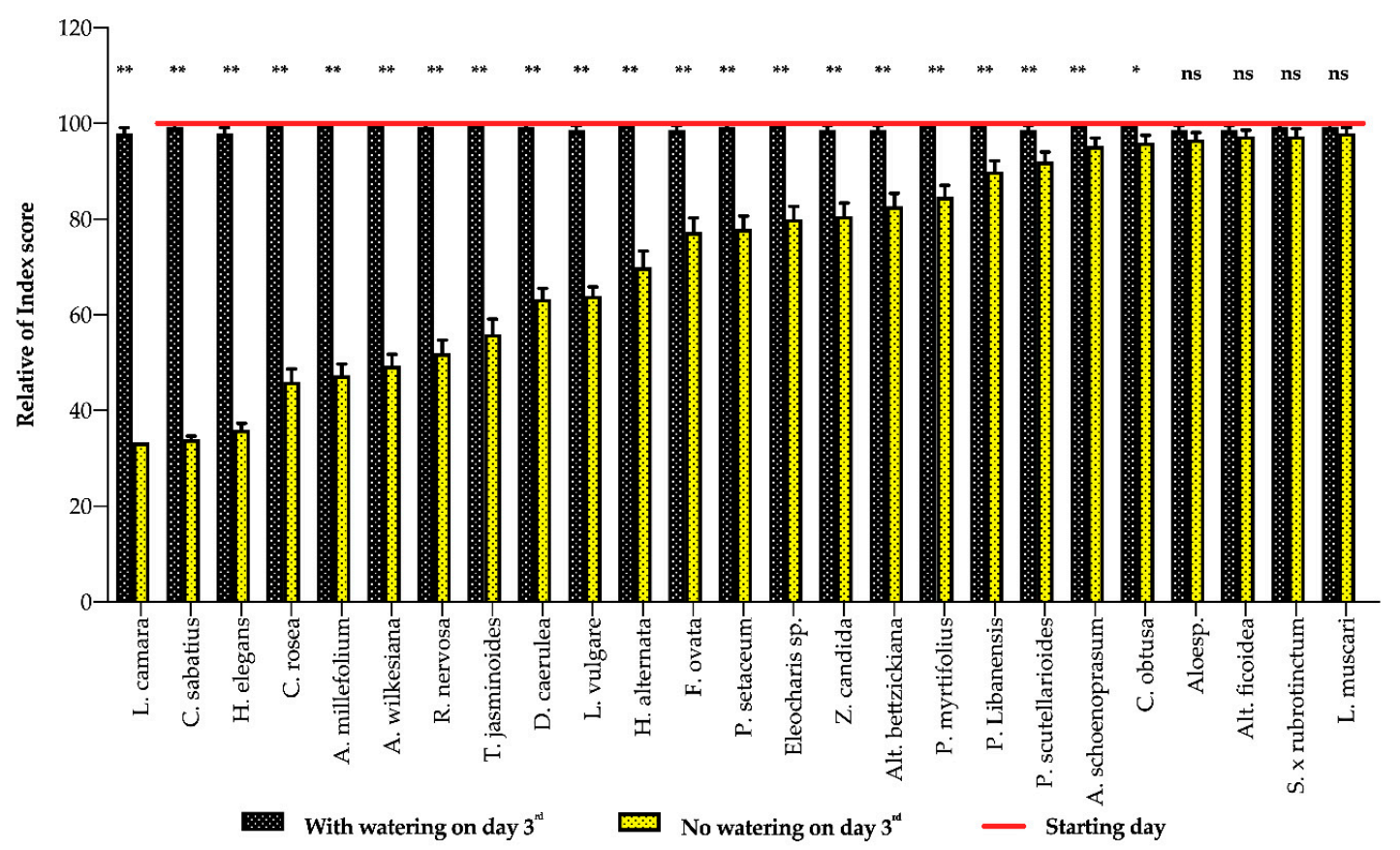

Figure 1. Effect of water deficiency on the relative aesthetic appeal index on the 3rd day of the experiment for different plant species. Bars and error bars represeant mean \pm SE. Non significant (ns) and significant differences $\left({ }^{*}\right.$ at $p<0.05$ and ${ }^{* *}$ at $p<0.01$ by Student's T-test between no watering at 3 days are shown above the bars.

Photosynthetic capacity reflects plant health since it is a prerequisite process for survival. Chlorophyll fluorescence values, popularly used for monitoring photosynthetic status under stress, include maximum quantum yield ( $\mathrm{Fv} / \mathrm{Fm})$ and the maximum darkadapted photochemical efficiency of photosystem II (PSII). Figure 3 shows the diverse response of relative $\mathrm{Fv} / \mathrm{Fm}$ (A) and PSII (B) values among plant species. P. myrtifolius noticeably increased Fv/Fm and PSII values under both conditions (with and without irrigation). However, eight plant species (i.e., P. libanensis, Eleocharis sp., F. ovata, P. setaceum, A. schoenoprasum, A. millefolium, Aloe sp. and S. x rubrotinctum) had small, needle-shaped leaves. Although Fv/Fm value has shown high potential as an indicator for water stress tolerance in previous studies [31], in the current study, we could not measure this value for plant species with small and narrow leaves due to the limitation of our equipment. The $\mathrm{Fv} / \mathrm{Fm}$ values, therefore, may not be a good candidate parameter for cluster analysis.

Leaf color was evaluated by total chlorophyll content and a color meter in SPAD units. Figure 4A shows the high total chlorophyll content values that were not significantly different between the well-irrigated and water-limited treatments for P. scutellarioides, T. jasminoides, A. wilkesiana, F. ovata, P. libanensis, P. myrtifolius, $S \times$ rubrotinctim, Z. candida, Alt. bettrzickiana, D. caerulea, Alt. ficoidea, P. setaceum and Aloe sp., except C. obtusa. In contrast, R. nervosa, Eleocharis sp., L. muscari, L. vulgare, C. rosea, A. millefolium, L. camara, H. alternata, H. elegans, A. schoenoprasum and C. sabatius leaves had significantly lower total chlorophyll content in the stressed plants compared to the well-watered plants. Changes in leaf color according to SPAD units indicated similar results (Figure 4B). However, two species (C. sabatius and L. camara) had different results when comparing the two methods. Moreover, the needle-shaped leaves of Eleocharis sp., F. ovata, A. schoenoprasum and A. millefolium, and the very thick leaf blades of Aloe sp. and S. x rubrotinctum prevented measurement via chlorophyll meter. 



C

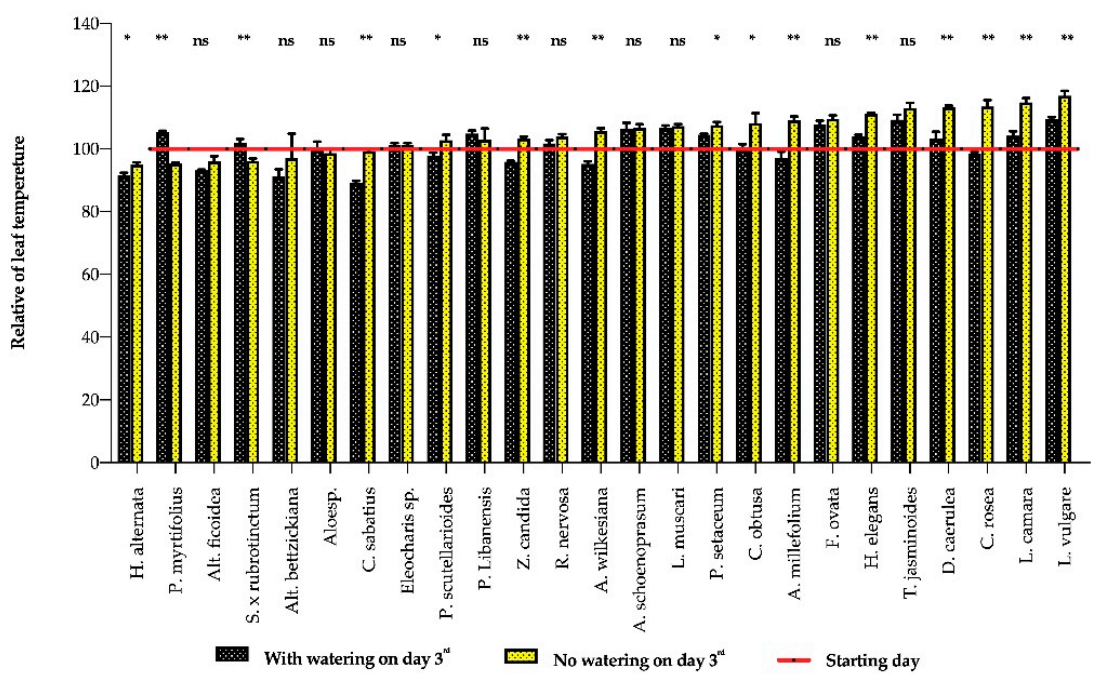

Figure 2. Effect of water deficiency on the relative water content index in leaves (A), percent stomata opening (B) and relative leaf temperature (C) on the 3rd day of the experiment for different plant species. Bars and error bars represeant mean \pm SE. Non significant (ns) and significant differences ${ }^{*}$ at $p<0.05$ and ${ }^{* *}$ at $p<0.01$ by Student's T-test between no watering at 3 days are shown above the bars. 


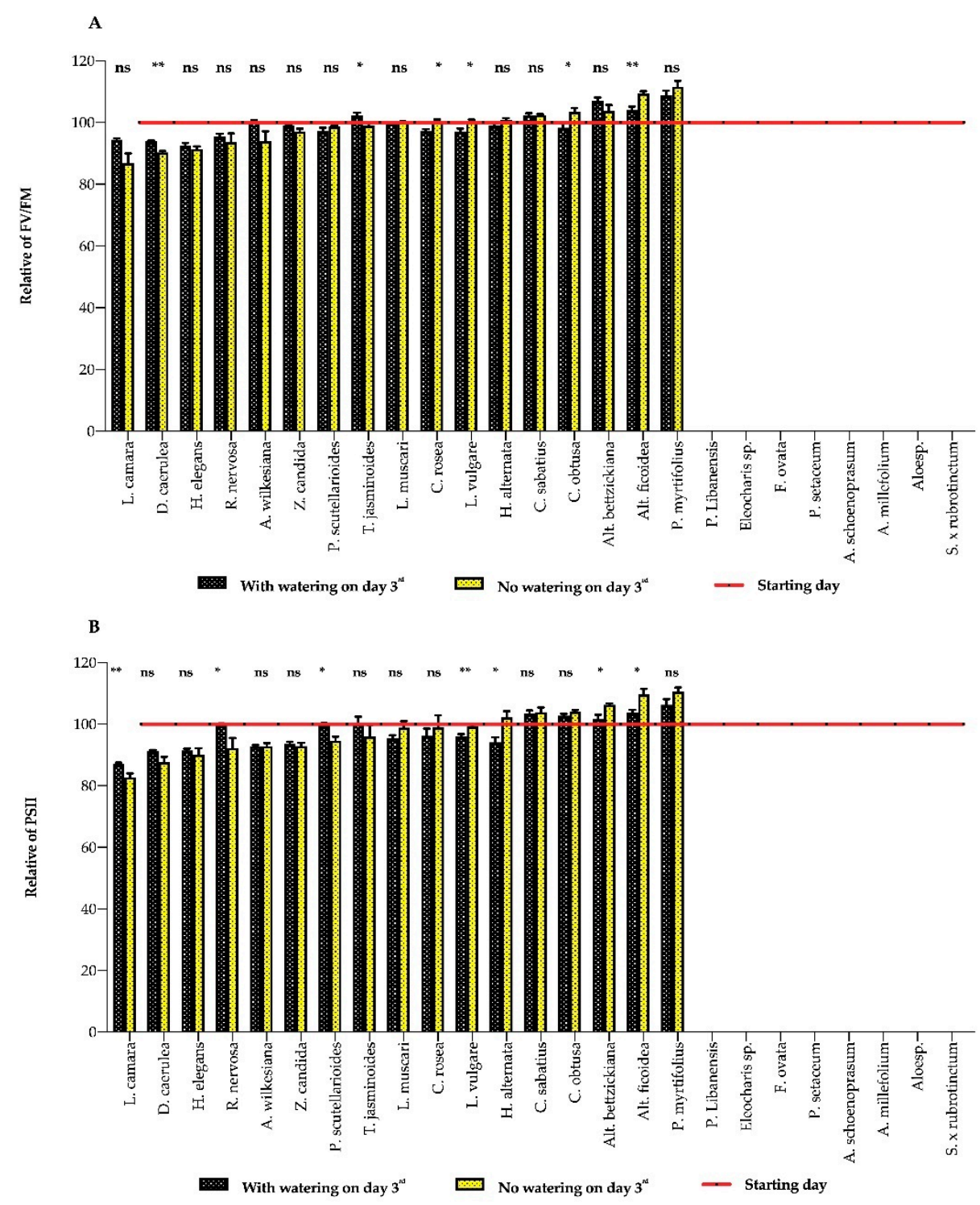

Figure 3. Effect of water deficiency on relative maximum quantum yield (Fv/Fm, A) and maximum dark-adapted photochemichal efficiency of photosystem II (PSII, B) on the 3rd day of the experiment for different plant species. Bars and error bars represeant mean $\pm \mathrm{SE}$. Non significant (ns) and significant differences ${ }^{*}$ at $p<0.05$ and ${ }^{* *}$ at $p<0.01$ by Student's T-test between no watering at 3 days are shown above the bars.

\subsection{Indicator Implements}

Leaf greenness, Fv/Fm, and PSII were not effective for evaluating plant response to water deficiency among the studied plant species in this non-irrigated rooftop model. The remaining five parameters that did show a response between the two treatments (with and without irrigation) were used in the hierarchical cluster analysis (Figure 5).

The values of three parameters under the water-deficit treatment (RWC, esthetic index, and percent stomatal opening) were found in the same clade. Meanwhile, the other clade was less conclusive, as it included the total leaf chlorophyll content and leaf surface temperature of both treatments. Thus, leaf RWC, esthetic index, and percent stomatal opening were deemed appropriate indicators for evaluating the water-deficit tolerance of the 25 ground cover plant species (Figure 5). Seven plant species, i.e., A. schoenoprasum, L. muscari, Aloe sp., S. x rubrotinctum, Alt. ficoidea, P. libanensis and P. scutellarioides appeared in the same clade when cluster analysis was performed (Figures 6 and A1), which confirms the accuracy of drought tolerance assessment under the present methodology. This high- 
endurance group was able to maintain high RWC and percent stomatal opening that was the same on day three as on the starting day, leading to high esthetic appeal scores.



Figure 4. Effect of water deficiency on relative total clorophyll content (A) and SPAD units (B) on the 3rd day of the experiment for different plant species. Bars and error bars represeant mean \pm SE. Non significant (ns) and significant differences ${ }^{*}$ at $p<0.05$ and ${ }^{* *}$ at $p<0.01$ by Student's T-test between no watering at 3 days are shown above the bars. 

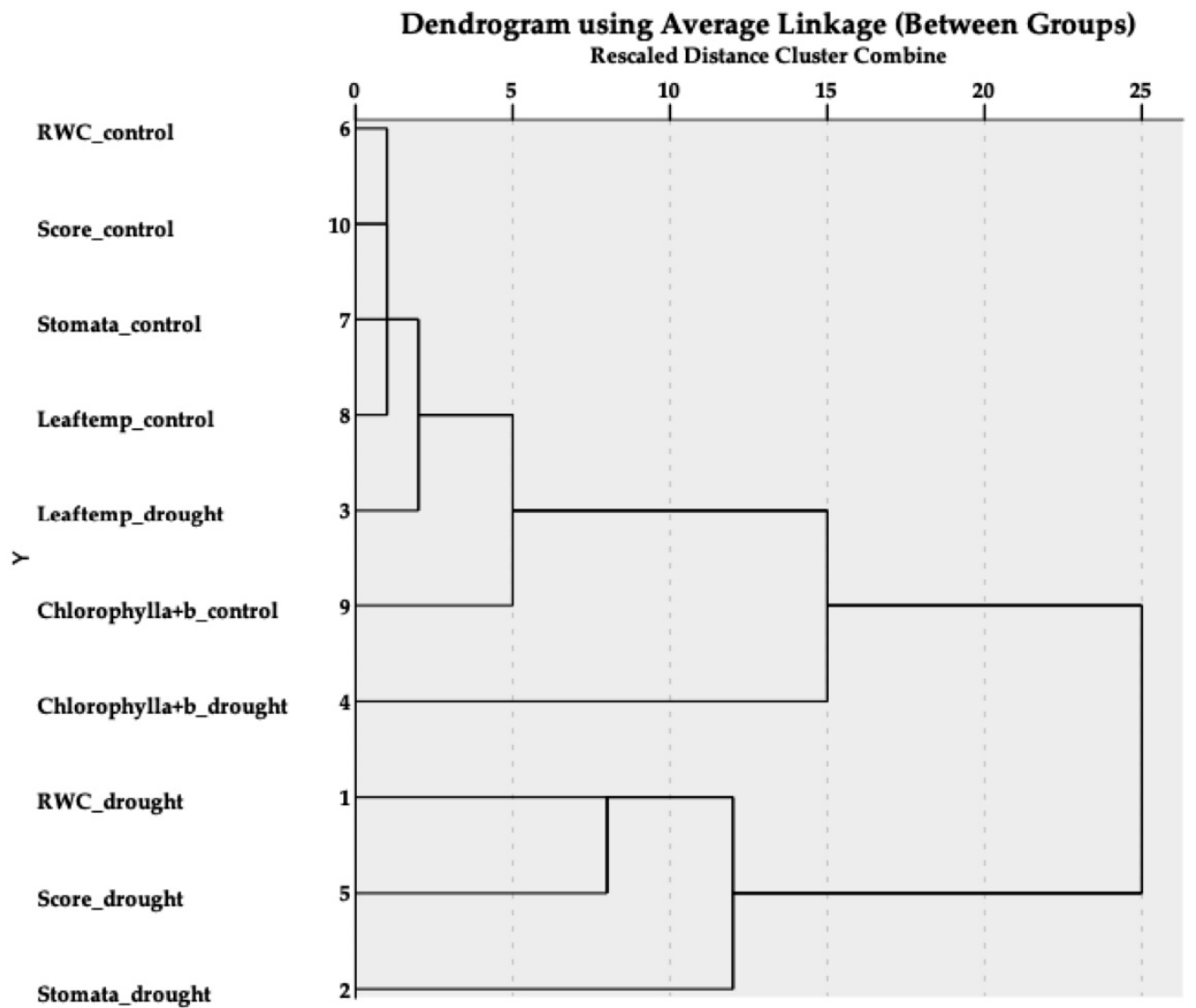

Figure 5. Cluster analysis of 5 criteria from 2 treatments (control and drought) using multivariable parametersunder Hierarchical cluster analysis (SPPS softwere). (RWC: relative water content, Score: aesthetic appeal, Leaftemp: leaf temperature , Chlorophyll $\mathrm{a}+\mathrm{b}$ : sum of chlorophyll a and b contents, Stomata: percent of opened stomata).

In contrast, 11 plant species (L. camara, H. elelgans, H alternata, C. sabatius, D. caerulea, A. millefolium, C. rosea, T. jasminoides, A. wilkesiana, R. nervosa, and L. vulgare) showed high sensitivity to water-limited environments, especially $\mathrm{H}$. alternata and $\mathrm{H}$. elegans, which became extremely wilted after water withdrawal (Figures 7, A2 and A3). Plants in the sensitive group required frequent irrigation, which is contrary to the other clade of the 7 drought-tolerant species. Additionally, plants in the intermediate group (C. obtusa, Eleocharis sp., F. ovata, Z. candida, P. setaceum, P. myrtifolius and Alt. Bettzickiana) (Figure A4) showed weakness associated with changes in percent stomatal opening, RWC, and esthetic appeal. Thus, leaf RWC, esthetic index, and percent stomatal opening are clearly suitable indicators to evaluate water-deficiency endurance among these ground cover species. 


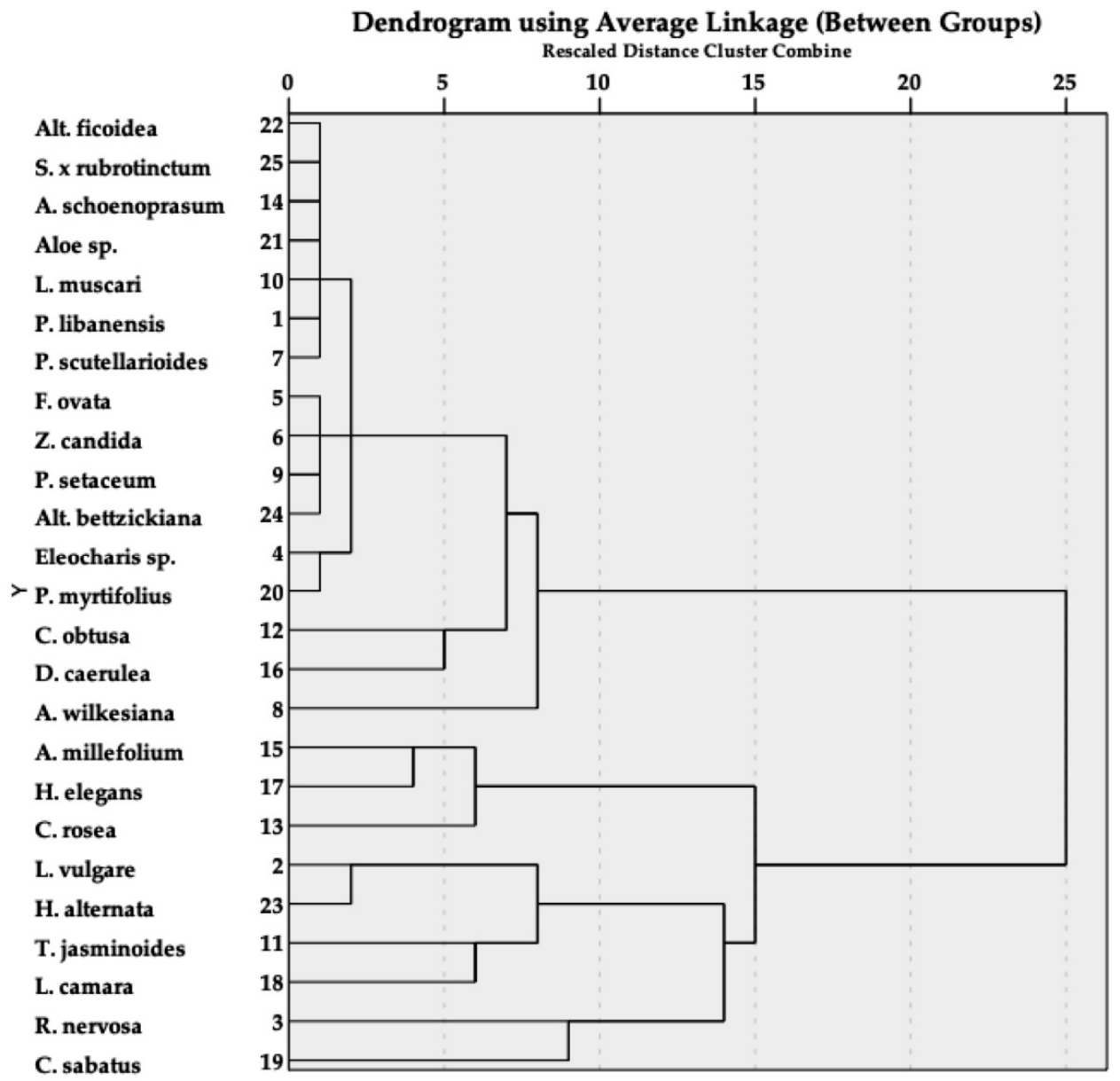

Figure 6. Cluster analysis of 25 ground cover species using multivariate parameters of leaf relative water content, aesthetic appeal, and percent stomata opening by Hierarchical cluster analysis of SPPS software.

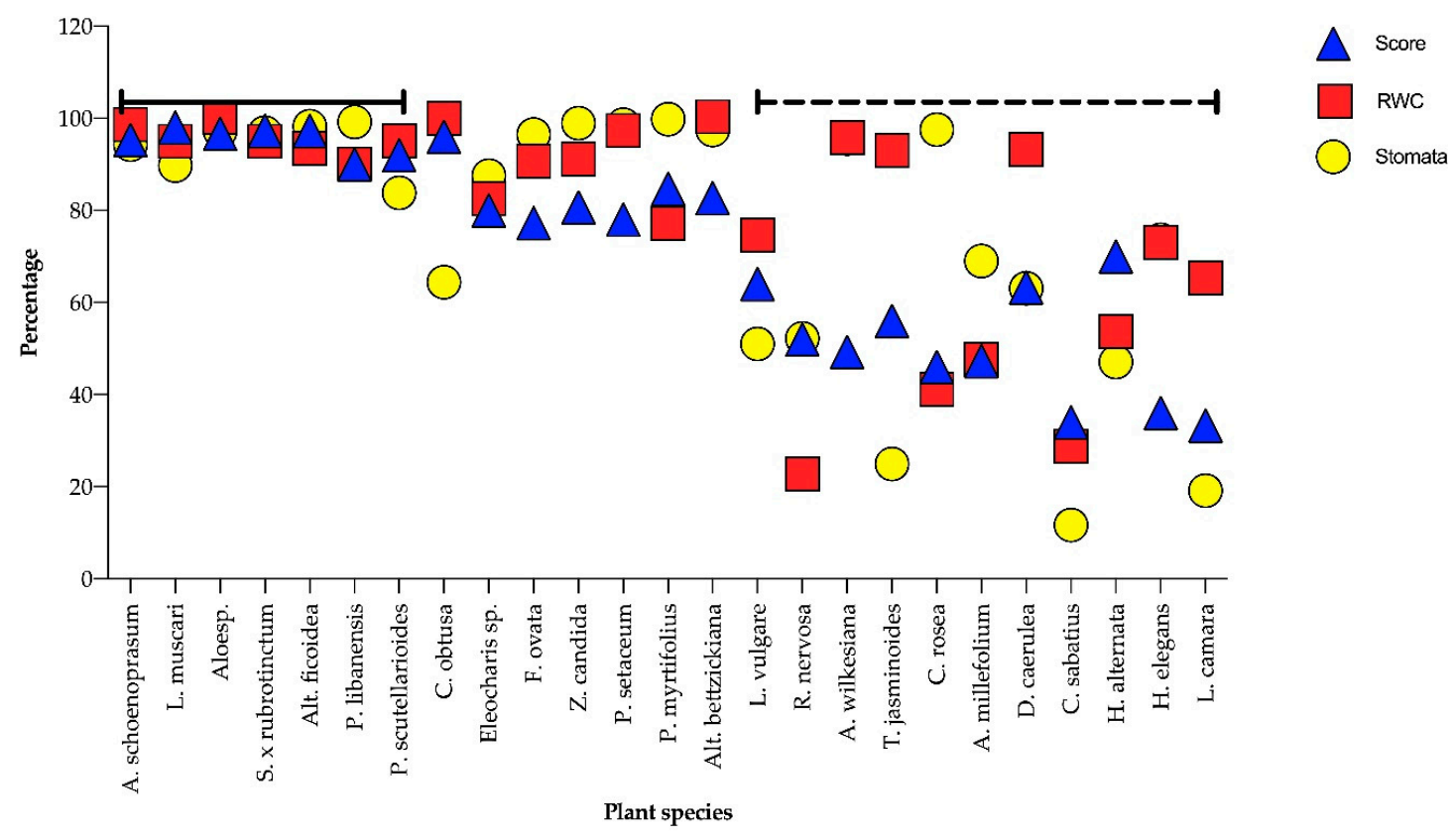

Figure 7. Classification of 25 ground cover species using 3 prameters (leaf relative water content: red, relative index of aesthethic appeal: blue, and percent stomata opening: yellow) for drought tolerant (solid line) and drought sensitive (dotted line) groups. 


\section{Discussion}

Plants can be divided into species that are sensitive and those that are tolerant towards abiotic stresses. The difference in response for crop plants is usually measured by yield, which is a complex trait determined by growth and developmental processes that are influenced by environmental signals throughout the life cycle [37]. However, in terms of landscape plant species, the beauty of plant appearance is also important for human appreciation. After stress exposure, each plant species has different mechanisms and abilities to cope with such stressors. Water status involves root absorption and stomatal conductance processes. Plants that are able to balance and regulate processes within related transport organs are ultimately able to successfully maintain homeostasis.

In this study, the responses on day 3 were diverse among the 25 plant species, with some species losing a considerable amount of water (the sensitive group), while tolerant species were able to survive drought conditions for longer periods. However, the methods with which the tolerant species coped with stress exposure were diverse. For example, A. schoenoprasum and Aloe sp. had high leaf relative water content (RWC) index values and percent stomatal opening similar to those of the starting day (Figure 2A). Although these two species have different genetic backgrounds and photosynthetic systems, they still had similar responses leading to high drought endurance. Interestingly, C. obtusa had high leaf RWC yet low stomatal opening (Figure 2B). The responses by different groups also corresponded to the soil moisture levels. In general, a large difference in the concentration of water vapor between the stomatal pores and the outside atmosphere affects plant-water relations and is the driving force for water movement through the soil-plant-atmosphere continuum [38]. This means that the stomatal apertures are a counterbalance to RWC, and both clearly react to water-deficiency exposure, leading them to be appropriate indicators.

Another known response to drought is for plants to adjust leaf area by accelerating senescence and leaf abscission. In this study, once the water was withdrawn, many plant species dropped older leaves prior to the plant exhibiting wilting. Reduced leaf size is generally considered to be beneficial to plants under water-deficit conditions because of a concomitantly reduced rate of transpiration, even though such leaf area reduction may impact the whole plant's photosynthetic rate [38]. However, in terms of relative leaf temperature on day 3 , the pattern changed intermittently and unpredictably, making these data less reliable.

Recently, monitoring chlorophyll fluorescence has been a widely-used method for evaluating photosynthesis [39]. Photosynthetic capacity is normally reduced after stress exposure, which is clearly demonstrated by information obtained through the chlorophyll fluorescence technique. The difference between control (irrigated) and water-deficient plants in Fv /Fm, PSII, chlorophyll level and SPAD corresponded with the period of water withdrawal, especially with regards to wilting or reduced aesthetic scores. Most stomatal apertures became narrower under drought conditions, likely causing photosynthetic interruption, similar to the results by Wang et al. [40], who reported that water-deficits affected the growth of potted pitaya (Hylocereus undatus) plants. The authors found that drought decreased total chlorophyll content, Fv/Fm, the frequency of opened stomata, and aperture size. Such evidence supports the role of photosynthesis-related parameters for plant tolerance of drought. After plants are subject to drought stress, stomatal conductance and net photosynthetic rate are reduced. The photosynthetic apparatus may be damaged, leading to declines in PSII photochemical efficiency. Plant growth rates, therefore, decrease gradually under water-deficit conditions [6].

Photosynthetic status, as measured by Fv/Fm and PSII, was a limitation of this study, as 8 of the 25 plant species had either a leaf shape or leaf thickness that prevented measurement of photosynthetic response. Moreover, the difference in these parameters between plants with and without irrigation was mostly insignificant. Although these parameters were valuable to report, their usefulness in detecting drought-tolerant plants is limited in this study model. The response in leaf greenness as measured by color meter had the same limitation (Figure 4B). In contrast to leaf greenness, total chlorophyll content 
showed a definitive pattern in sequence changes across plant species and stress conditions (Figure 4A). Therefore, evaluating leaf color by total chlorophyll analysis is more suitable for detecting stress response than quantifying all leaf color components through a color meter. For example, P. scutellariodes leaves, which contain various pigments, showed higher total chlorophyll levels on day three under both treatments (irrigated and nonirrigated) compared to day zero, while SPAD values remained unchanged. Drought typically damages photosynthetic pigments, including chlorophyll; however, some studies have reported an increase in chlorophyll content following drought. It seems to depend on crop species and cultivar [41] whether or not photosynthetic pigments are reliable indicators for evaluating stress endurance.

Cluster analysis using multivariate characters is commonly used to identify effective criteria for classifying plants as tolerant or sensitive to stress. Many studies aiming to identify tolerant lines from genetic resources have used multivariate criteria at both vegetative and reproductive stages. It has generally been recommended that the best criteria for the identification of stress tolerance in a crop species include multiple indices. For example, salt-tolerance in Indica rice (Oryza sativa L.) can be detected using pigment degradation, and chlorophyll a fluorescence diminution [42] and salt-tolerance in wheat can be detected using multiple agronomic parameters such as tiller number, leaf number, and leaf area per plant during the vegetative stage; dry weight per plant during the vegetative, reproductive, and mature stages; and yield components of the main spike and total grain yield at maturity [10]. For genotype evaluation in a breeding program of peach (Prunus persica (L.) Batsch) under highland conditions in Thailand, dry root weight and sorbitol concentration can be used to screen for drought-tolerant rootstocks [43].

Leaf RWC, esthetic index, and percent stomata opening all fell within the same clade, with significant sequence differences observed among the 25 plant species under 2 irrigation conditions. Seven plant species, namely, A. schoenoprasum, L. muscari, Aloe sp., S. $x$ rubrotinctum, Alt. ficoidea, P. libanensis and P. scutellarioides belonged to the tolerant group and had high RWC in leaves as well as having a high percentage of open stomata, causing them to have the most endurance and high esthetic appeal. This result agrees with many reports on the stress-tolerance abilities of landscaping species.

Consistent with our results, the seven plant species in the tolerant group have also been reported as being able to endure stressful conditions. First, $A$. schoenoprasum was reported to be low-maintenance and is used extensively in US rooftop gardens. Second, L. muscari in Singapore was reported to have a drought-tolerant character. Third, S. x rubrotinctum, a kind of Sedum, is a popular choice as this succulent plant is well-adapted to the conditions often found on green roofs due to its ability to limit transpiration and store excess water [2]. Finally, Aloe sp. and Alt. ficoidea are also low-maintenance, and P. scutellarioides is tolerant to heavy shade. No information has been reported for P. libanensis, but it showed good tolerance to water-limitation. In contrast to our results, several landscaping plant species have been reported as being low-maintenance or tolerant to drought or heavy shade, such as T. jasminoides, A. millefolium, C. rosea, L. vulgare, A. wilkesiana, H. alternata, D. caerulea, C. sabatius, H. elegans and L. camara, but these species performed poorly under the methodology used in this study. Interestingly, C. obtusa, a native plant species in Sri Lanka, was reported to exhibit good adaptability to drought conditions yet was grouped in the intermediate class in this study because the soil moisture content fell sharply to $50 \%$ on day 3 with a low stomata opening rate [11,44-48]. Such results mean that in this rooftop model, seven plant species that were reported to be drought-tolerant were not able to cope with water-deficit conditions. Most information on drought-tolerant or low-maintenance landscape plants has been reported from studies conducted in temperate climates or wellmaintained systems. The adaptability of each plant is therefore likely diverse depending on the culture environment with which its metabolism must interact and respond. This study aimed to create an extreme environment in a tropical climate in order to screen for potential ground cover species that may be useful for future use underwater shortage conditions or climate change. 


\section{Conclusions}

This study was able to evaluate the water-deficit tolerance of ground cover plants under a non-irrigated rooftop model by using three suitable indicators (leaf relative water content, esthetic index, and percent stomata opening) after withholding irrigation for three days. Seven plant species were classified in the highly tolerant group and showed high endurance as well as a high esthetic appeal under these conditions, namely, Allium schoenoprasum, Liriope muscari, Aloe sp., Sedum x rubrotinctum, Alternanthera ficoidea, Pilea libanensis and Plectranthus scutellarioides. The drought-resistance response of these species appeared due to successful maintenance of the higher percentage of the stomata that remain open and their ability to counterbalance leaf relative water content. Such traits favor their use as landscape plants with the prolonged esthetic appeal. Finally, photosynthetic responses (e.g., maximum quantum yield, light quantum yield, leaf greenness, and total chlorophyll content) were unreliable parameters for drought evaluation of landscaping ground cover plants under the rooftop model.

Author Contributions: Conceptualization, methodology, formal analysis, investigation, resources, visualization, N.P. and A.P.; writing — original draft preparation, N.P.; writing-review and editing, A.P. Both authors have read and agreed to the published version of the manuscript.

Funding: This research received no external funding.

Data Availability Statement: Data is contained within the article.

Acknowledgments: We thank Kanokrat Nusawas for data collection, Watcharra Chintakovid, Wanichaya Chaiwimol and Sunipa Detpitthayanan for data analysis and preparation, Supachai Amka for analysis of the growing media, and Alyssa B. Stewart for proofreading the English.

Conflicts of Interest: The authors declare no conflict of interest.

\section{Appendix A}

Table A1. Esthetic scores of 25 plant species under the drought treated condition at 1, 3, 5, and 7 days after the start of the experiment. (3: the maximum degree of a healthy plant exhibiting as the starting day. Significant difference $\left(^{*}\right)$ at $p<0.05$ by Student's t-test from the control plant).

\begin{tabular}{|c|c|c|c|c|c|}
\hline \multirow{2}{*}{ No } & \multirow{2}{*}{ Scientific Name } & \multicolumn{4}{|c|}{ Days after the Start of the Drought } \\
\hline & & 1 & 3 & 5 & 7 \\
\hline 1 & $\begin{array}{c}\text { Hemigraphis alternata (Burm.f.) T. Anderson } \\
\text { (Syn.) (Strobilanthes alternata (Burm.f.) Moylan } \\
\text { ex J.R.I. Wood) }\end{array}$ & $2.86^{*}$ & $1.86^{*}$ & 1.38 * & 1.00 * \\
\hline 2 & Alternanthera bettzickiana (Regel) G. Nicholson & $2.78^{*}$ & $2.48 *$ & $1.56^{*}$ & 1.00 * \\
\hline 3 & Alternanthera ficoidea (L.) P. Beauv. & 2.98 & 2.92 & $2.62 *$ & 1.50 * \\
\hline 4 & Allium schoenoprasum L. & 2.94 & $2.86 *$ & $2.70 *$ & 2.12 * \\
\hline 5 & Zephyranthes candida (Lindl.) Herb. & $2.76^{*}$ & $2.42 *$ & 1.54 * & $1.36^{*}$ \\
\hline 6 & Trachelospermum jasminoides (Lindl.) Lem. & 2.96 & $1.68 *$ & 1.08 * & 1.02 * \\
\hline 7 & Liriope muscari (Decne.) LH. Bailey & 3.00 & 2.94 & 2.86 & $2.56^{*}$ \\
\hline 8 & Aloe sp. & 2.94 & 2.90 & 2.90 & 2.90 \\
\hline 9 & Dianella caerulea Sims & $2.88^{*}$ & $1.90 *$ & $1.42 *$ & $1.14^{*}$ \\
\hline 10 & Achillea millefolium $\mathrm{L}$. & $2.78 *$ & $1.42 *$ & $1.02 *$ & 1.00 * \\
\hline 11 & Coreopsis rosea Nutt. & $2.70 *$ & $1.38 *$ & $1.02 *$ & 1.00 * \\
\hline 12 & Leucanthemum vulgare (Vaill.) Lam. & $2.72 *$ & $1.92 *$ & 1.12 * & 1.00 * \\
\hline 13 & Cyanotis obtusa (Trimen) Trimen (Syn.) & 2.94 & $2.88 *$ & 2.74 * & $2.48 *$ \\
\hline
\end{tabular}


Table A1. Cont.

\begin{tabular}{|c|c|c|c|c|c|}
\hline \multirow{2}{*}{ No } & \multirow{2}{*}{ Scientific Name } & \multicolumn{4}{|c|}{ Days after the Start of the Drought } \\
\hline & & 1 & 3 & 5 & 7 \\
\hline 14 & Convolvulus sabatius Viv. & $2.16^{*}$ & $1.00 *$ & $1.00 *$ & 1.00 * \\
\hline 15 & Sedum $x$ rubrotinctum R.T. Clausen & 2.96 & 2.94 & 2.94 & 2.94 \\
\hline 16 & Fimbristylis ovata (Burm.f.) J.Kern & $2.78^{*}$ & $2.32 *$ & $1.30 *$ & 1.10 * \\
\hline 17 & Rhynchospora nervosa (Vahl) Boeckeler & $2.48 *$ & $1.56^{*}$ & $1.06^{*}$ & 1.00 * \\
\hline 18 & Eleocharis sp. & $2.90 *$ & $2.40 *$ & $1.84 *$ & $1.14^{*}$ \\
\hline 19 & Acalypha wilkesiana Müll.Arg. & $2.84^{*}$ & $1.48^{*}$ & $1.00 *$ & 1.00 * \\
\hline 20 & Plectranthus scutellarioides (L.) R.Br. & $2.90 *$ & $2.76^{*}$ & $2.22 *$ & 1.04 * \\
\hline 21 & Heterocentron elegans Kuntze & $1.44^{*}$ & $1.08^{*}$ & $1.00 *$ & 1.00 * \\
\hline 22 & Phyllanthus myrtifolius (Wight) Müll.Arg. & 2.98 & $2.54 *$ & $1.42 *$ & 1.00 * \\
\hline 23 & $\begin{array}{l}\text { Pennisetum setaceum (Forssk.) Chiov. (Syn.) } \\
\text { (Cenchrus setaceus (Forssk.) Morrone.) }\end{array}$ & 2.64 * & 2.34 * & $1.30 *$ & $1.02 *$ \\
\hline 24 & Pilea libanensis Urb. & $2.88 *$ & $2.70 *$ & $2.36^{*}$ & 1.04 * \\
\hline 25 & Lantana camara $\mathrm{L}$. & $1.52 *$ & 1.00 * & $1.00 *$ & 1.00 * \\
\hline
\end{tabular}

A

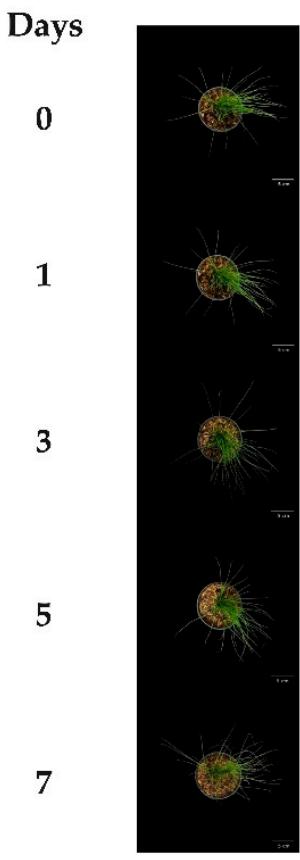

B

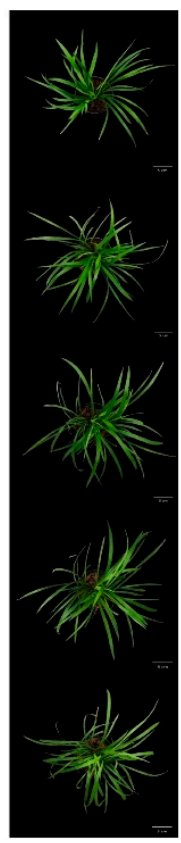

C

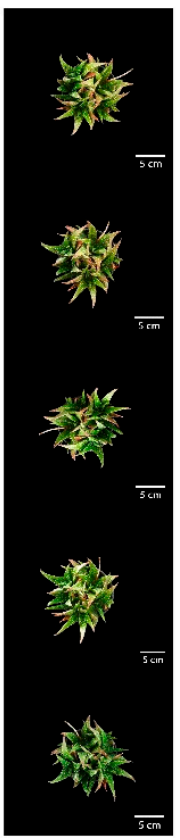

D

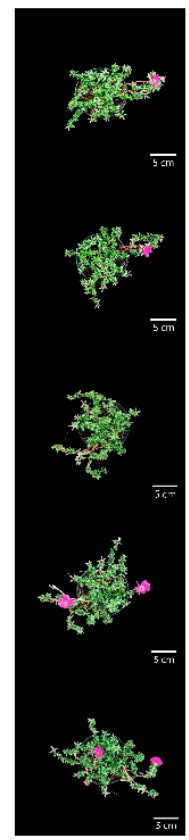

E



F

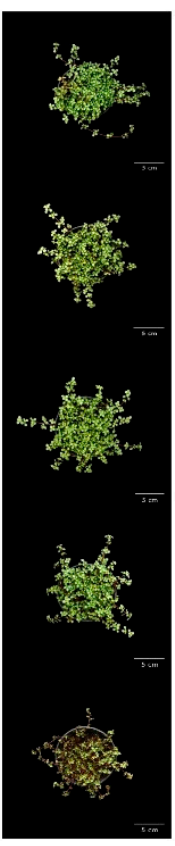

G

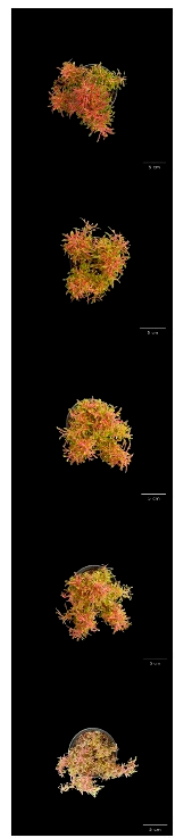

Figure A1. Images of plants under the drought stress treated condition at 5 time intervals: 0, 1, 3, 5, and 7 days after the start of the experiment (Allium schoenoprasum: A, Liriope Muscari: B Aloe Sp: C, Sedum x rubrotinctum: D, Alternanthera ficodea: E, Pilea libanensis: F, Plectranthus scutellarioides: G). 
A

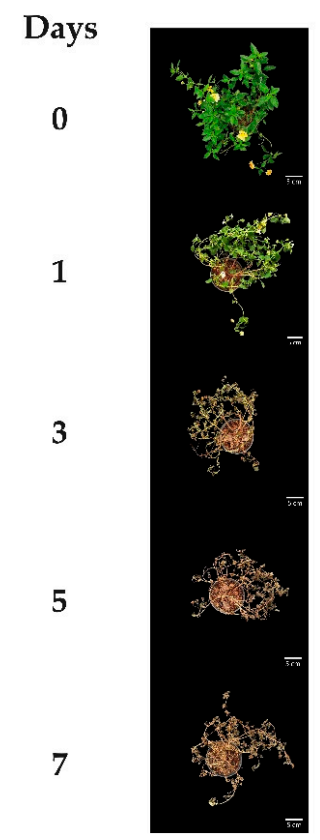

B

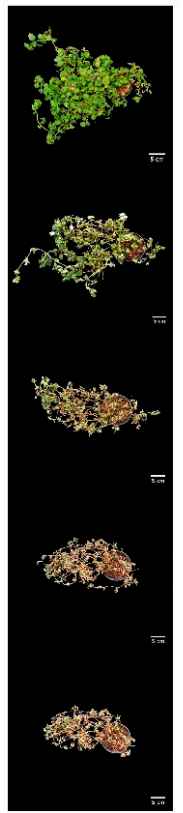

C

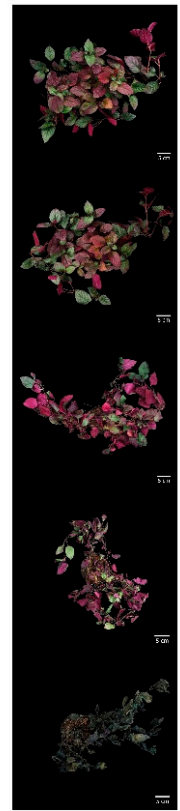

D

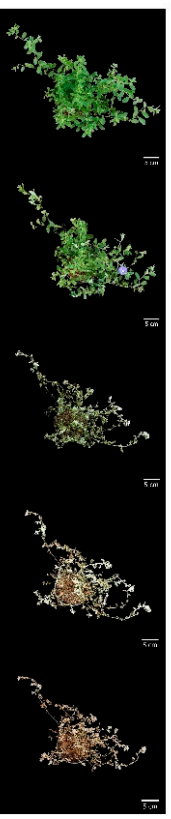

E

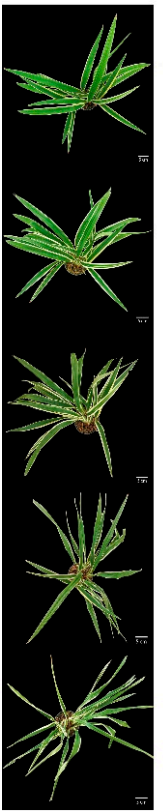

F

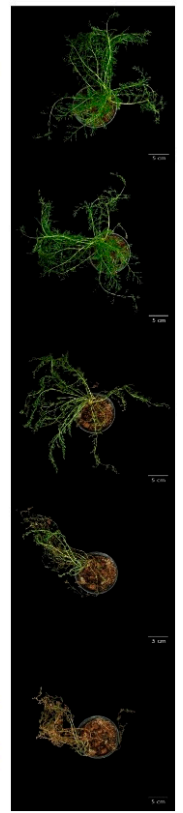

Figure A2. Images of plants under the drought treated conditions at 5 time intervals: 0, 1, 3, 5, and 7 days after the start of the experiment (Lantana camara: A, Heterocentron elegans: B, Hemigraphis alternata: C: Convolvulus sabitus: D, Dianella caerulea: E, Achillea millefolium.

A

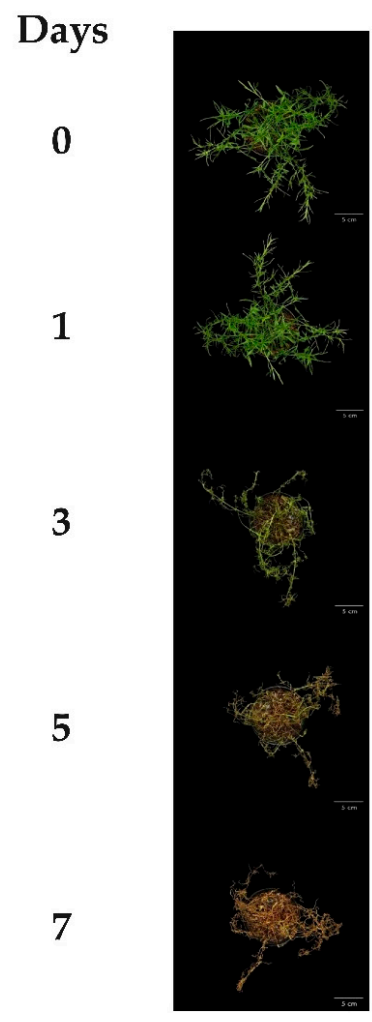

B

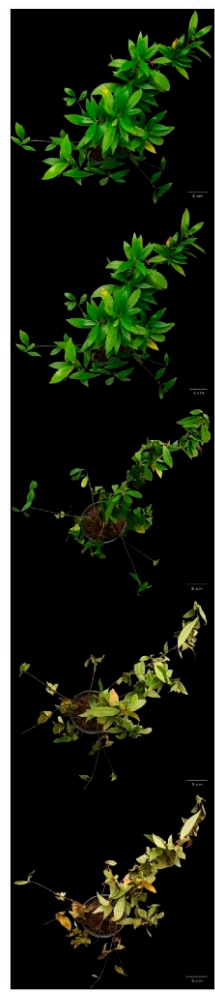

C

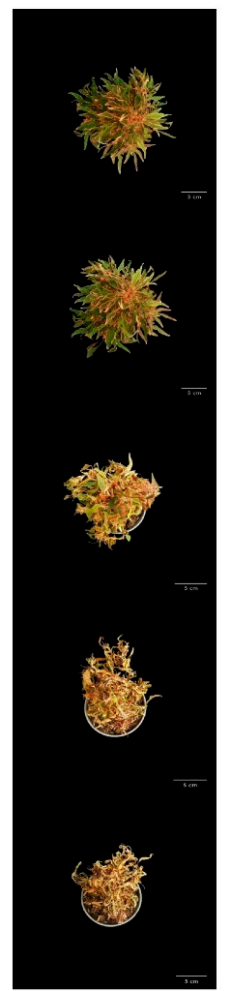

D

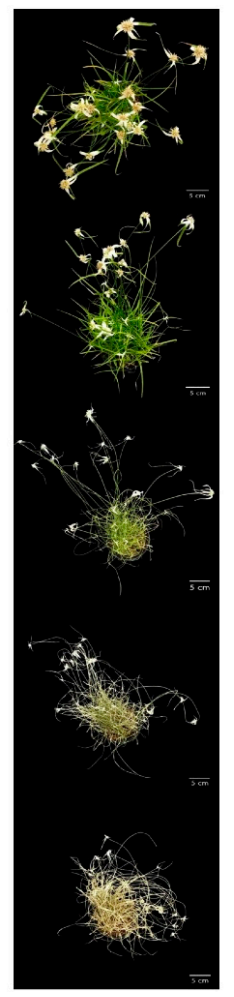

E

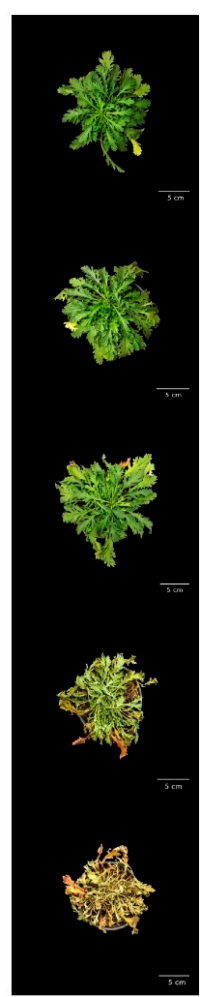

Figure A3. Images of plants under the drought treated condition at 5 times intervals: $0,1,3,5$, and 7 days after of the start of the experiment (Coreopsis rosea: A, Trachelospermum jasminoides: B, Acalypha wilkesiana: C, Rhymchospora nervosa: D, Leucanthemum vulgare: E). 
A

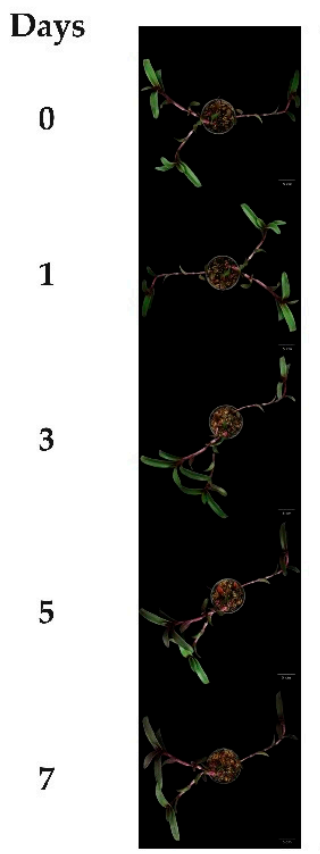

B

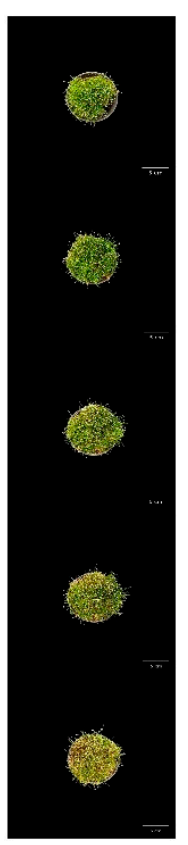

C

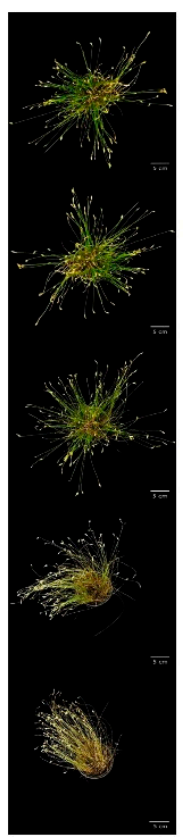

D

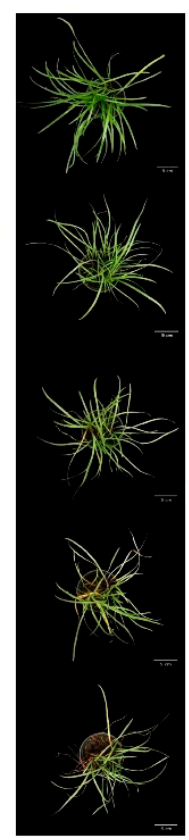

E

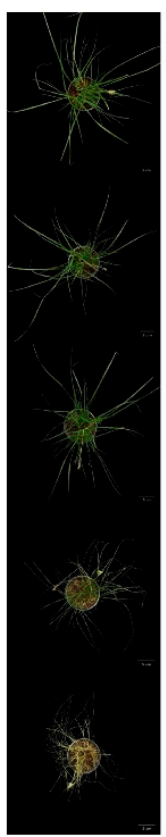

F

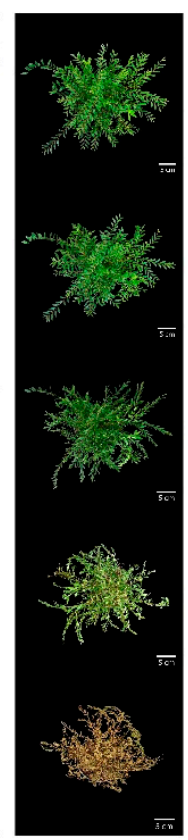

G

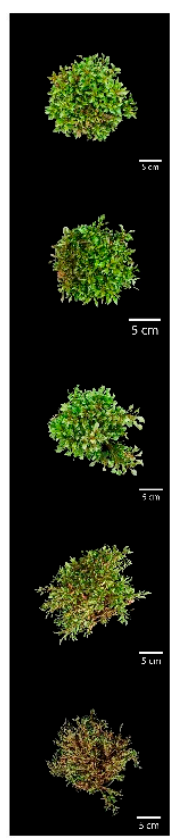

Figure A4. Images of plants under the drought treated condition at 5 time intervals: 0, 1, 3, 5 and 7 days after the sytart of the experiment (Coreopsis rosea: A, Trachelospermum jasmonides: B, Acalypha wilkesiana: C, Rynchosphora nervosa: D, Leucanthemum vulgare: E).

\section{References}

1. Jongtanom, Y.; Kositanont, C.; Baulert, S. Temporal variations of urban heat island intensity in three major cities, Thailand. Mod. Appl. Sci. 2011, 5, 105. [CrossRef]

2. Getter, K.L.; Rowe, D.B. The Role of Extensive Green Roofs in Sustainable Development. HortScience 2006, 41, 1276. [CrossRef]

3. Fathi, M.; Masnavi, M. Assessing environmental aesthetics of roadside vegetation and scenic beauty of highway landscape: Preferences and perception of motorists. Int. J. Environ. Res. 2014, 8, 941-952.

4. Klett, J.E.; Wilson, C.R. Xeriscaping: Ground Cover Plants. Ph.D. Thesis, Colorado State University Extension, Fort Collin, CO, USA, 2007.

5. Oraee, A.; Tehranifar, A. Evaluating the potential drought tolerance of pansy through its physiological and biochemical responses to drought and recovery periods. Sci. Hortic. 2020, 265, 109225. [CrossRef]

6. Xu, Z.; Zhou, G.; Shimizu, H. Plant responses to drought and rewatering. Plant Signal. Behav. 2010, 5, 649-654. [CrossRef] [PubMed]

7. Mir, R.R.; Zaman-Allah, M.; Sreenivasulu, N.; Trethowan, R.; Varshney, R.K. Integrated genomics, physiology and breeding approaches for improving drought tolerance in crops. Theor. Appl. Genet. 2012, 125, 625-645. [CrossRef] [PubMed]

8. Dichio, B.; Xiloyannis, C.; Sofo, A.; Montanaro, G. Osmotic regulation in leaves and roots of olive trees during a water deficit and rewatering. Tree Physiol. 2006, 26, 179-185. [CrossRef] [PubMed]

9. Juan, M.; Rivero, R.M.; Romero, L.; Ruiz, J.M. Evaluation of some nutritional and biochemical indicators in selecting salt-resistant tomato cultivars. Environ. Exp. Bot. 2005, 54, 193-201. [CrossRef]

10. El-Hendawy, S.E.; Hu, Y.; Yakout, G.M.; Awad, A.M.; Hafiz, S.E.; Schmidhalter, U. Evaluating salt tolerance of wheat genotypes using multiple parameters. Eur. J. Agron. 2005, 22, 243-253. [CrossRef]

11. Getter, K.L.; Rowe, D.B. Selecting Plants for Extensive Green Roofs in the United States; Michigan State University Extension: E. Lansing, MI, USA, 2008.

12. Ornamental Plant, Landscape, Exotic Plant, Rare Plant. Available online: http:/ / docnursery.com/home.html (accessed on 17 January 2021).

13. Hemigraphis Alternata. Available online: http://www.missouribotanicalgarden.org/PlantFinder/PlantFinderDetails.aspx? taxonid=275316 (accessed on 21 October 2020).

14. Alternanthera Ficoidea. Available online: http://www.missouribotanicalgarden.org/PlantFinder/PlantFinderDetails.aspx? taxonid=275668 (accessed on 21 October 2020).

15. Allium Schoenoprasum. Available online: https://www.missouribotanicalgarden.org/PlantFinder/PlantFinderDetails.aspx? kempercode $=\mathrm{j} 270$ (accessed on 21 October 2020).

16. Zephyranthes Candida. Available online: http://www.missouribotanicalgarden.org/PlantFinder/PlantFinderDetails.aspx? kempercode $=\mathrm{c} 747$ (accessed on 21 October 2020). 
17. Trachelospermum Jasminoides. Available online: http://www.missouribotanicalgarden.org/PlantFinder/PlantFinderDetails. aspx?kempercode $=$ a155 (accessed on 21 October 2020).

18. Liriope Muscari. Available online: https://www.missouribotanicalgarden.org/PlantFinder/PlantFinderDetails.aspx? kempercode=1100 (accessed on 21 October 2020).

19. Aloe Vera. Available online: http:/ / www.missouribotanicalgarden.org /PlantFinder $/$ PlantFinderDetails.aspx?kempercode=b628 (accessed on 21 October 2020).

20. Dianella Caerulea-Blue Flax Lily. Available online: https://www.gardeningwithangus.com.au/dianella-caerulea/ (accessed on 22 October 2020).

21. Achillea Millefolium. Available online: https://www.missouribotanicalgarden.org/PlantFinder/PlantFinderDetails.aspx? kempercode=b282 (accessed on 21 October 2020).

22. Coreopsis rosea. Available online: http://www.missouribotanicalgarden.org/PlantFinder/PlantFinderDetails.aspx? kempercode $=\mathrm{s} 150$ (accessed on 21 October 2020).

23. Leucanthemum vulgare 'Maikonigin' MAY QUEEN. Available online: http:/ / www.missouribotanicalgarden.org/PlantFinder/ PlantFinderDetails.aspx taxonid=250182\&isprofile $=0 \&$ (accessed on 21 October 2020).

24. Cyanotis Obtusa Trimen. Available online: https:/ / www.nparks.gov.sg/florafaunaweb/flora/6/9/6924 (accessed on 22 October 2020).

25. Convolvulus Sabatius. Available online: https://www.perennials.com/plants/convolvulus-sabatius.html (accessed on 22 October 2020).

26. Sedum x Rubrotinctum. Available online: https://www.rhs.org.uk/Plants/16987/i-Sedum-i-times;-i-rubrotinctum-i/Details (accessed on 22 October 2020).

27. Eleocharis sp. (montevidensis) - Tropica Aquarium Plants. Available online: https://www.birstall.co.uk/products/tropicaeleocharis-sp-montevidensis-.html (accessed on 22 October 2020).

28. Acalypha Wilkesiana. Available online: http://www.missouribotanicalgarden.org/PlantFinder/PlantFinderDetails.aspx? kempercode $=\mathrm{a} 478$ (accessed on 21 October 2020).

29. Plectranthus Scutellarioides. Available online: http://www.missouribotanicalgarden.org/PlantFinder/PlantFinderDetails.aspx? kempercode $=\mathrm{a} 547$ (accessed on 21 October 2020).

30. Heterocentron Elegans. Available online: http://www.surinenglish.com/lifestyle/201801/05/heterocentron-elegans-2018010510 5108-v.html (accessed on 22 October 2020).

31. Pennisetum Setaceum 'Rubrum'. Available online: http://www.missouribotanicalgarden.org/PlantFinder/PlantFinderDetails. aspx?kempercode $=\mathrm{c} 257$ (accessed on 21 October 2020).

32. Lantana Camara. Available online: https://www.missouribotanicalgarden.org/PlantFinder/PlantFinderDetails.aspx? kempercode $=\mathrm{a} 523$ (accessed on 21 October 2020).

33. Meetam, M.; Sripintusorn, N.; Songnuan, W.; Siriwattanakul, U.; Pichakum, A. Assessment of physiological parameters to determine drought tolerance of plants for extensive green roof architecture in tropical areas. Urban For Urban Green 2020, 56, 126874. [CrossRef]

34. Turner, N.C. Techniques and experimental approaches for the measurement of plant water status. Plant Soil 1981, 58, 339-366. [CrossRef]

35. Abràmoff, M.D.; Magalhães, P.J.; Ram, S.J. Image processing with ImageJ. Biophotonics Int. 2004, 11, 36-42.

36. Sumanta, N.; Haque, C.I.; Nishika, J.; Suprakash, R. Spectrophotometric analysis of chlorophylls and carotenoids from commonly grown fern species by using various extracting solvents. Res. J. Chem. Sci. 2014, 4, 63-69.

37. Dolferus, R. To grow or not to grow: A stressful decision for plants. Plant Sci 2014, 229, 247-261. [CrossRef] [PubMed]

38. Forni, C.; Duca, D.; Glick, B.R. Mechanisms of plant response to salt and drought stress and their alteration by rhizobacteria. Plant Soil 2017, 410, 335-356. [CrossRef]

39. Maxwell, K.; Johnson, G.N. Chlorophyll fluorescence-A practical guide. J. Exp. Bot. 2000, 51, 659-668. [CrossRef] [PubMed]

40. Wang, L.; Zhang, X.; Ma, Y.; Qing, Y.; Wang, H.; Huang, X. The highly drought-tolerant pitaya (Hylocereus undatus) is a nonfacultative CAM plant under both well-watered and drought conditions. J. Hortic. Sci. Biotechnol. 2019, 94, 643-652. [CrossRef]

41. Fahad, S.; Bajwa, A.A.; Nazir, U.; Anjum, S.A.; Farooq, A.; Zohaib, A.; Sadia, S.; Nasim, W.; Adkins, S.; Saud, S.; et al. Crop Production under Drought and Heat Stress: Plant Responses and Management Options. Front. Plant Sci. 2017, 8, 1147. [CrossRef] [PubMed]

42. Cha-um, S.; Boriboonkaset, T.; Pichakum, A.; Kirdmanee, C. Multivariate physiological indices for salt tolerance classification in indica rice (Oryza sativa L. spp. indica). Gen. Appl. Plant Physiol. 2009, 35, 75-87.

43. Boonanunt, S.; Krisanapook, K.; Boonprakob, U.; Pichakum, A.; Phavaphutanon, L. Suitable criteria for drought-tolerant peach rootstocks grown in northern Thailand. Maejo Int. J. Sci. 2014, 8, 190-197. [CrossRef]

44. Broussard, M.C. A Horticultural Study of Liriope and Ophiopogon: Nomenclature, Morphology and Culture; Lousiana State University and Agricultural and Mechanical College: Baton Rouge, LA, USA, 2007.

45. Domenghini, J.C.; Bremer, D.J.; Fry, J.D.; Davis, G.L. Prolonged Drought and Recovery Responses of Kentucky Bluegrass and Ornamental Groundcovers. HortScience 2013, 48, 1209. [CrossRef]

46. Greeshma, G.M.; Murugan, K. Desiccation tolerance in Artillery Plant (Pilea microphylla (L.) Liebm): A search. Int. Res. J. Environ. Sci. 2015, 4, 26-32. 
47. Tan, P.Y.; Sia, A. A pilot green roof research project in Singapore. In Proceedings of the Third Annual Greening Rooftops for Sustainable Communities Conference, Awards and Trade Show, Washington, DC, USA, 4 May 2005.

48. Wadugodapitiya, A.; Weeratunga, V.; de Goonatilake, S.A.; Chandranimal, D.; Perera, N.; Asela, C. Insights into the Biodiversity of the Sampur Area in Trincomalee; IUCN, International Union for Conservation of Nature: Columbo, Sri Lanka, 2013 ; p. 15. 